
мукозального иммунитета при хронической обструктивной болезни легких ранней стадии

Уральская государственная медицинская академия дополнительного образования, г. Челябинск

\author{
G.L.Ignatova, L.A.Stepanishcheva, Yu.O.Pechenkina
}

\title{
Effects of fenspirid on some parameters of mucosal immunity in patients with early-stage chronic obstructive pulmonary disease
}

\begin{abstract}
Summary
The aim of this study was to evaluate influence of fenspirid on clinical and immune parameters of early-stage COPD. Workers (all were males) from a large machine-building enterprise of Chelyabinsk having stable COPD stage I or II participated in the study. They were randomized in 2 groups: 30 patients received fenspirid $80 \mathrm{mg}$ b.i.d. and 30 patients received placebo (calcium gluconate) b.i.d. during 6 months. We assessed the patients' complaints, severity of cough and dyspnea, sputum volume, lung function parameters, measured saliva concentrations of final NO metabolites using

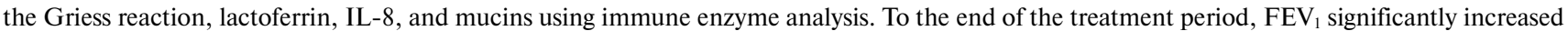
in the fenspirid group (from $57.42 \pm 1.66 \%$ до $61.93 \pm 2.59 \% ; p<0.05$ ) whereas it did not change significantly in the placebo group. Clinical improvement (reduction in cough, sputum volume, dyspnea, wheeze) was noted in 26 patients (86.6 \%) and 16 patients (53.3\%), respectively. Lactoferrin concentration decreased from $486.01 \pm 60.59$ to $96.40 \pm 10.17 \mu \mathrm{g} \mathrm{ml}^{-1}(p<0.05)$, IL-8 decreased from $111.7 \pm 16.68$ to $41.90 \pm 6.60$ $\mu \mathrm{g} \mathrm{ml}^{-1}(p<0.05)$, mucin protein concentration increased from $110.8 \pm 13.28$ to $298.4 \pm 33.14 \mu \mathrm{g} \mathrm{ml}^{-1}(p<0.05), \mathrm{NO}_{\mathrm{x}}$ decreased from $11.21 \pm 0.91$ to $6.15 \pm 2.06 \mu \mathrm{mol} \mathrm{L}^{-1}(p<0.05)$. These parameters in the placebo group changed nonsignificantly. Exacerbations of COPD occurred in 6 patients (20\%) of fenspirid group and 10 patients $(33.3 \%)$ of the placebo group during the study period. Tolerance of the drug was generally good. Thus, fenspirid has significant antiinflammatory effect, improves clinical signs of COPD and FEV ${ }_{1}$. The results suggest that fenspirid could be useful in early-stage COPD patients.
\end{abstract}

\section{Резюме}

Цель исследования - определить влияние фенспирида на клинико-иммунологические характеристики заболевания у пациентов ХОБЛ ранних стадий. В исследовании участвовали мужчины - рабочие крупного машиностроительного предприятия г. Челябинска со впервые выявленной ХОБЛ 1-й и 2-й степеней в стабильном состоянии, которые методом случайной выборки были разделены на 2 группы: 30 человек получали фенспирид по 80 мг 2 раза в день в течение 6 месяцев, контрольная группа $(n=30)$ получала плацебо (глюконат кальция) 2 раза в день в течение 6 месяцев. Ежемесячно оценивали жалобы, выраженность кашля и одышки, количество мокроты, параметры функции внешнего дыхания, в слюне измеряли концентрацию конечных стабильных метаболитов оксида азота (NO) с помощью реакции Гриса, лактоферрина, интерлейкина-8 (IL-8), муцина с помощью иммуноферментного анализа. K концу лечения в группе фенспирида существенно уменьшилась бронхиальная обструкция (объем форсированного выдоха за 1-ю с (ОФВ $)$

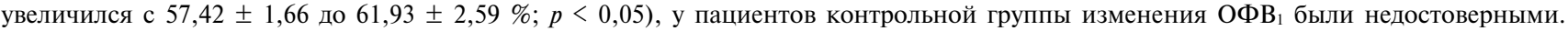
Клинический эффект (уменьшение кашля, мокроты, одышки, сухих хрипов в легких) отмечался у 26 (86,6 \%) больных, получавших фенспирид, и у 16 (53,3 \%) пациентов группы плацебо. В группе фенспирида снизилась концентрация лактоферрина с 486,01 \pm 60,59 до 96,40 $\pm 10,17$ мкг/мл ( $p<0,05)$, IL-8 - с 111,7 $\pm 16,68$ до 41,90 $\pm 6,60$ мкг/мл $(p<0,05)$, увеличилась концентрация белка муцина

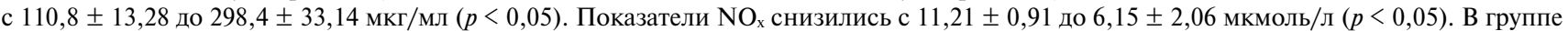
плацебо динамика этих показателей недостоверна. Обострения ХОБЛ за период лечения развивались у 6 (20\%) пациентов группы фенспирида и у 10 (33,3\%) пациентов группы плацебо. Переносимость препарата в целом была хорошей. Таким образом, фенспирид обладает выраженным противовоспалительным действием, уменьшает выраженность клинических признаков ХОБЛ, повышает ОФВ Полученные данные свидетельствуют о целесообразности использования препарата в лечении больных ХОБЛ на ранних стадиях.

Хроническая обструктивная болезнь легких (ХОБЛ) является одной из актуальных проблем современного здравоохранения и одной из основных причин смерти от хронических заболеваний во всем мире $[1,2]$. Она оказывает существенное влияние на качество и продолжительность жизни пациентов. ХОБЛ наносит значительный ущерб, связанный с утратой трудоспособности, наиболее активной части населения [3].

Главным механизмом развития и прогрессирования ХОБЛ является хроническое воспаление. Как один из основных типовых процессов, воспаление - это результат реакции на повреждающий агент, формирующий основные морфологические проявления болезни $[2,4]$. Известно, что бронхиальная обструкция при ХОБЛ имеет необратимый и обратимый характер. Обратимый компонент бронхиальной обструкции связан с воспалением и характерным спазмом гладкой мускулатуры бронхов, отеком слизистой и гиперсекрецией слизи, возникающей под влиянием большого спектра провоспалительных медиаторов, таких как интерлейкин-8 (IL-8), фактор некроза опухоли $\alpha$, нейтрофильная протеаза и свободные радикалы [5]. Необратимый компонент 
бронхиальной обструкции определяется эмфиземой и перибронхиальным фиброзом, который неуклонно нарастает. Персистирующие микроорганизмы в бронхиальном дереве являются важным элементом в поддержании хронического воспаления [6, 7].

Изучение различных адаптационных механизмов, так или иначе участвующих в процессе пато- и саногенеза локального бронхолегочного иммунитета, требует изучения [8, 9]. Микробоцидный барьер слизистой оболочки респираторного тракта - важный компонент врожденного иммунитета, который формирует одну из наиболее эффективных линий микробной защиты. К веществам антиадгезивного действия, снижающим уровень колонизации патогенных микроорганизмов, относят муцин [10]. Его биосинтез осуществляется специальными экзокринными бокаловидным клетками с интроэпителиальным расположением. Муцин в составе вязкого геля растекается по поверхности слизистой оболочки, хорошо адсорбируя различные частицы (пыль, микроорганизмы), предотвращая их прикрепление к поверхности и внедрение в глубокие слои покровных тканей [11].

В последние годы изучена роль NO в патологии легких [12]. Показано, что оксид азота (NO), выделяемый эндотелиальными клетками, участвует в регуляции тонуса и структуры легочных сосудов [13]. Образованный макрофагами и эндотелиальными клетками NO способствует бронходилатации - преимущественно крупных бронхов [14]. Также NO участвует в антимикробной защите бронхиального дерева и регуляции цилиарного транспорта как необходимое звено для усиления биения ресничек [15].

Лактоферрин относят к белкам острой фазы; его изучение перспективно в области легочной патологии в качестве маркера активности воспаления, а также наступающих осложнений [16, 17]. Этот железосодержащий гликопротеин обладает способностью связывать ионы железа и другие металлы, чем можно объяснить его бактерицидное и антиэндотоксиновое действие [18]. В литературе имеются сведения, характеризующие лактоферрин как регулятор клеточных и гуморальных иммунологических реакций [19]. Все вышеперечисленные провоспалительные факторы мукозального иммунитета у лиц, страдающих ХОБЛ, являются маркерами воспаления с тенденцией к хронизации процесса.

Эффективность лечебных мер по прекращению прогрессирования ХОБЛ в полной мере зависит от возможностей лечения хронического воспаления. Классическая терапия ХОБЛ в настоящее время не располагает методами, способными тормозить прогрессирование болезни. Парадокс заключается в том, что из всего арсенала средств и методов главным является назначение бронходилататоров, не обладающих прямым противовоспалительным действием [2]. В глобальной инициативе GOLD пересмотра 2003 г. эксперты отмечают, что исследование клеточных и молекулярных механизмов воспаления для поиска лекарственных средств, способных тормозить хроническое воспаление, лежащее в основе
ХОБЛ, - это одно из важнейших направлений исследований. Среди современных средств воздействия на аномальный воспалительный процесс при ХОБЛ особое место занимает препарат фенспирид (Эреспал).

Цель данного исследования - определить влияние фенспирида на клинико-иммунологические характеристики заболевания у пациентов с ХОБЛ на ранних стадиях.

\section{Материалы и методы}

В ходе анкетирования, проводимого в рамках программы "Профилактика и лечение бронхолегочной патологии у работников ОАО "Уралтрак-ЧТЗ", разработанной коллективом кафедры терапии, фтизиопульмонологии и профпатологии ГОУ ДПО УГМАДО и сотрудниками городской поликлиники № 8 ОАО ЧТЗ "Уралтрак" в 2002 г., были обследованы 2584 рабочих крупного машиностроительного предприятия г. Челябинска.

В данную работу из общего числа обследованных пациентов были включены мужчины с впервые выявленной ХОБЛ 1-й и 2-й стадий в стадии ремиссии, требующие амбулаторного лечения и профилактики дальнейшего прогрессирования заболевания. Методом случайной выборки испытуемые были разбиты на 2 группы. Пациентам 1-й, основной, группы $(n=30)$ назначали фенспирид в дозе 80 мг 2 раза в день в течение 6 месяцев. Во 2-й группе - группе сравнения $(n=30)$ - больные получали плацебо, в качестве которого принимался глюконат кальция по 1 таблетке 2 раза в день в течение 6 месяцев.

Критерии включения больных в исследование:

- ежедневный кашель, часто с мокротой;

- бронхиальная обструкция, обратимость - не менее $12 \%$;

- функциональные признаки ХОБЛ (по данным спирографии): снижение отношения объема форсированного выдоха за 1-ю с к форсированной жизненной емкости легких (ОФВ 1 / ФЖЕЛ) $<70 \%$ в период ремиссии заболевания трижды на протяжении года;

- отсутствие в анамнезе типичных приступов удушья и / или атопии;

- отсутствие других заболеваний, сопровождающихся одышкой и кашлем (бронхоэктатическая болезнь, туберкулез);

- получение информированного согласия пациента на участие в исследовании.

Критерии исключения:

- обострение хронических заболеваний, а также тяжелые формы сопутствующих заболеваний.

В обеих группах проводимая предшествующая терапия (муколитики, редкий прием бронхолитиков) была малоэффективной, и у всех пациентов к началу лечения сохранялись клинические и лабораторные признаки заболевания вне обострения. Для оценки эффективности терапии в группах ежемесячно анализировались жалобы больного, осуществлялся общий осмотр (оценивалась выраженность кашля, 
одышки и количество отделяемой мокроты). Выраженность клинических симптомов заболевания оценивали в баллах [20].

\section{Инструментальные и функциональные методы исследования \\ Исследование ФВД}

Параметры функции внешнего дыхания (ФВД) регистрировались с помощью спирографа Microspiro-GP (Япония). После записи спирограммы определялись следующие показатели: пиковая скорость выдоха (ПСВ), ОФВ 1 , ФЖЕЛ, ОФВ 1 / ФЖЕЛ. ПроводиЛся бронходилатационный тест с применением 200800 мкг сальбутамола и оценивалось его влияние на показатели кривой "поток-объем" и на показатель $\mathrm{OФB}_{1}[21]$. Для расчета бронходилатационного ответа в соответствии с рекомендациями использовался параметр ОВ $_{1}[22]$.

\section{Исследование мукозального иммунитета}

Уровень продукции эндогенного NO оценивали по концентрации конечных стабильных метаболитов NO в препарате слюны посредством реакции Гриса. Количественное определение общего белка и муцина слюны определялось по методу Э.Н.Коробейниковой (2002 г.), определение лактоферрина, IL-8 проводилось с помощью иммуноферментного анализа.

\section{Статистические методы}

Статистическая обработка полученных результатов выполнена с помощью пакета программ Statistica 6.0 с расчетом среднего арифметического значения $(M)$, ошибки среднего $(m)$, критерия Стьюдента.

\section{Результаты и обсуждение}

На момент включения в исследование сформированные группы не различались по анамнестическим и клиническим параметрам. Средний возраст участников составил 57,16 $\pm 2,68$ года в 1-й группе и $55,80 \pm 1,90$ года во 2-й группе. К моменту окончания лечения в 1-й группе отмечено существенное уменьшение явлений бронхиальной обструкции, что выражалось в достоверном повышении значения $\mathrm{OФВ}_{1}$ (с 76,42 \pm 1,66 до 83,33 $\pm 2,59 \%$; $\left.p<0,05\right)$. У пациентов 2-й группы была зарегистрирована тен-

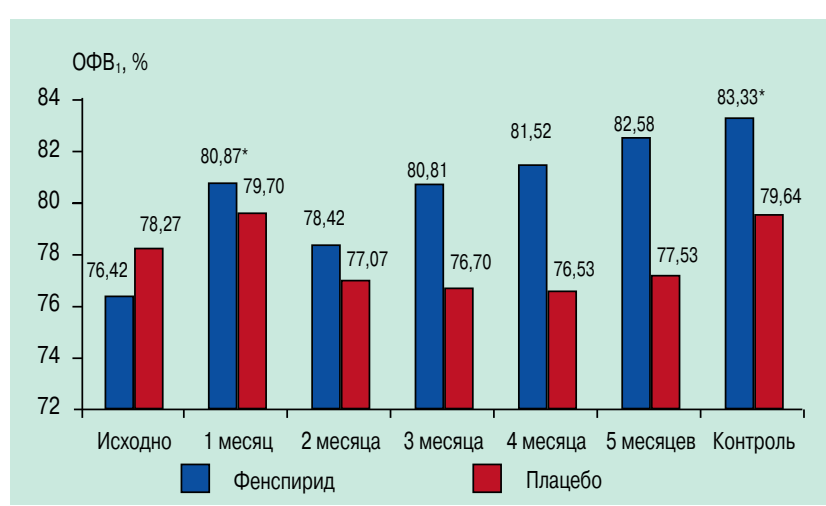

Рис. 1. Динамика ОФВ 1 за время лечения в обеих группах Примечание: ${ }^{*}-p<0,05$ по сравнению с исходными показателями.

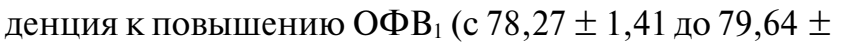
$2,79 \%)$, как показано на рис. 1.

Следует отметить, что, в отличие от данных E.И.Шмелева [2], в нашем исследовании отмечено повышение ОФВ 1 сразу через 1 месяц от начала лечения (с 76,42 $\pm 1,66$ до 80,87 $\pm 1,74 \%$; $p<0,05$; затем, на 3-м месяце наблюдения, значение этого показателя уменьшается, но к концу 6-го месяца остается достоверно повышенным.

К моменту окончания лечения клинический эффект отмечался у 26 (86,6 \%) больных, получавших фенспирид, а также у $16(53,3 \%)$ пациентов в группе плацебо, что проявлялось в уменьшении интенсивности кашля, уменьшении и / или прекращении отделения мокроты, выраженности одышки, в значительном уменьшении либо исчезновении сухих хрипов в легких. Клинический эффект лечения в группе, принимавшей плацебо, возможно, обусловлен интенсивной психологической работой с пациентами: ежемесячный осмотр, беседы о факторах, усугубляющих течение заболевания, вреде курения табака (рис. 2). Критериями оценки результатов мукозального иммунитета явились изменения изучаемых параметров слюны. В группе пациентов, принимавших фенспирид, снизилось количество лактоферрина с 486,01 $\pm 60,59$ мкг/мл в начале до $96,40 \pm 10,17$ мкг/мл в конце терапии $(p<0,05)$ и количество IL-8 с 111,7 \pm 16,68 до 41,90 \pm 6,60 мкг/мл соответственно $(p<0,05)$. Количество белка муцина в данной группе увеличилось с 110,8 $\pm 13,28$ до $298,4 \pm 33,14$ мкг/мл $(p<0,05)$, как показано на рис. 3.

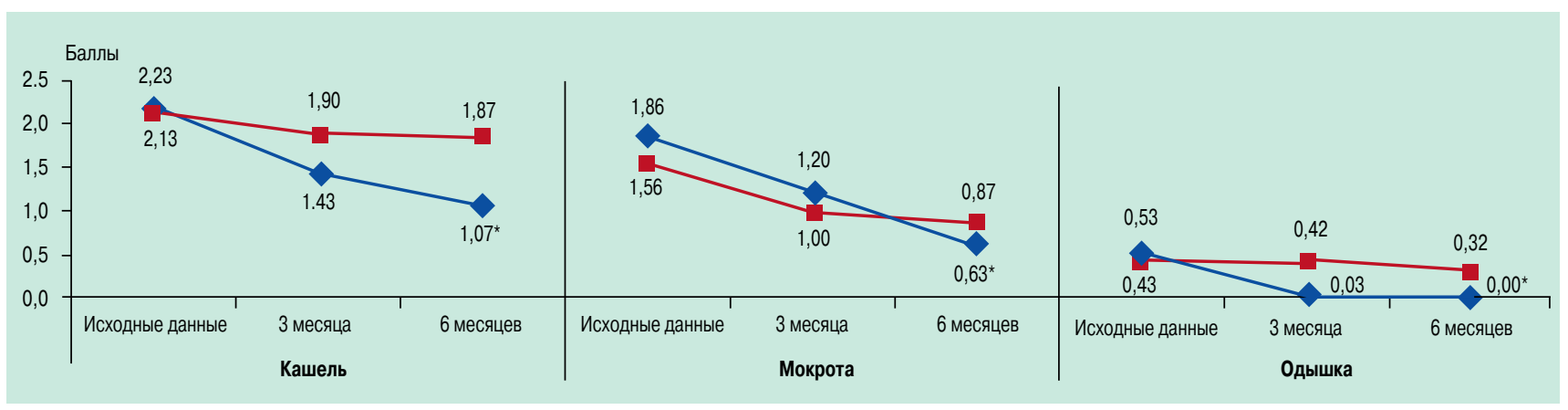

Рис. 2. Сравнительная динамика клинических показателей у больных ХОБЛ в группе фенспирида и контрольной группе: выраженность кашля, мокроты, одышки в баллах

Примечание: * $-p<0,05$ в сравнении с исходными показателями. 


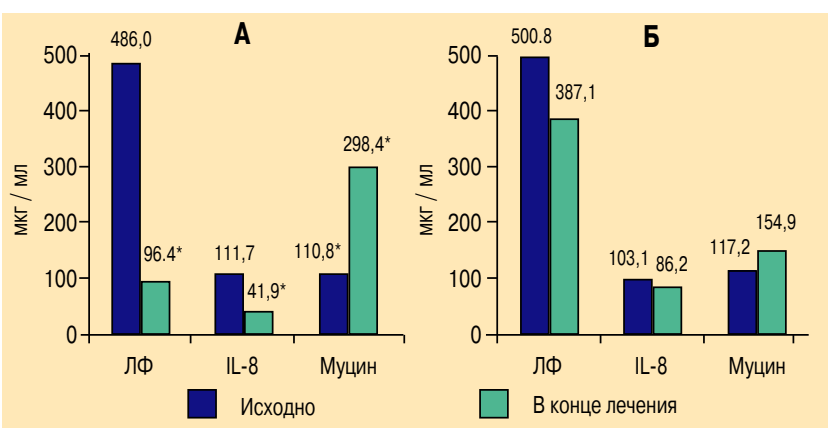

Рис. 3. Некоторые показатели мукозального иммунитета (лактоферрин, IL-8, муцин) в обеих группах (А - группа фенспирида, Б - контрольная группа) до и после лечения

Примечание: * $-p<0,05$ по сравнению с исходными показателями.

При измерении уровня эндогенного NO были отмечены снижение показателей $\mathrm{NO}_{\mathrm{x}} \mathrm{c} 11,21 \pm 0,91$ мкмоль/л в начале до $6,15 \pm 2,06$ мкмоль/л в конце лечения $(p<0,05)$ и лишь тенденция к изменению показателей конечных NO: уровень $\mathrm{NO}_{2}$ составил 7,28 \pm 0,42 и 4,07 $\pm 1,76$ мкмоль/л соответственно $(p>0,05)$, количество $\mathrm{NO}_{3}$ изменилось соответственно с 9,96 \pm 0,77 до 5,02 \pm 0,42 мкмоль/л $(p>0,05)$ - эти данные представлены на рис. 4. В контрольной группе, получавшей плацебо, наблюдались тенденция к снижению лактоферрина с 500,8 $\pm 60,93$ до 387,1 \pm 31,87 мкг/мл $(p>0,05)$, тенденция к увеличению муцина с 117,2 $\pm 13,83$ до 154,9 $\pm 15,26$ мкг/мл $(p>0,05)$ и тенденция к уменьшению количества IL-8 c $103,1 \pm 17,39$ до 86,2 $\pm 21,5$ мкг/мл $(p>0,05)$ с начала к концу исследования соответственно (рис. 3). Также была зарегистрирована тенденция к снижению показателей количества $\mathrm{NO}: \mathrm{NO}_{\mathrm{x}}-\mathrm{c} 10,94 \pm$ 1,12 до $6,02 \pm 1,83$ мкмоль/л $(p>0,05), \mathrm{NO}_{2}-$ с 7,23 \pm 0,46 до 5,08 \pm 0,42 мкмоль/л $(p>0,05), \mathrm{NO}_{3}-$ с 8,72 \pm 0,89 до 4,09 $\pm 1,75$ мкмоль/л $(p>0,05)$, как показано на рис. 4.

\section{Влияние терапии на обострения ХОБЛ}

За время наблюдения в обеих группах были зарегистрированы случаи обострения ХОБЛ: в 1-й группе - у 6 (20\%) пациентов, во 2-й - у 10 (33,3 \%) больных. Клиническими признаками обострения считались: усиление выраженности кашля, появление гнойной и слизисто-гнойной мокроты, усиление одышки, снижение показателей ОФВ 1 . Количество выданных листов нетрудоспособности составило в группах $2(33,3 \%)$ и 7 (70 \%) соответственно. Надо отметить, что симптомы обострения заболевания в 1-й группе купировались быстрее, чем во 2-й группе, что в дальнейшем значительно сократило период нетрудоспособности.

\section{Переносимость терапии}

Общая переносимость терапии в группах была хорошей. В 1-й группе у 2 (6,6 \%) пациентов отмечались диспепсические расстройства, у 3 (10\%) человек сонливость, у 1 (3,3\%) больного - чувство нехватки воздуха после приема препарата. Во 2-й группе 1 (3 \%) пациент жаловался на горечь во рту после приема препарата. Указанные нежелательные явления купировались симптоматическими средствами и прекратились после адаптации к препарату.

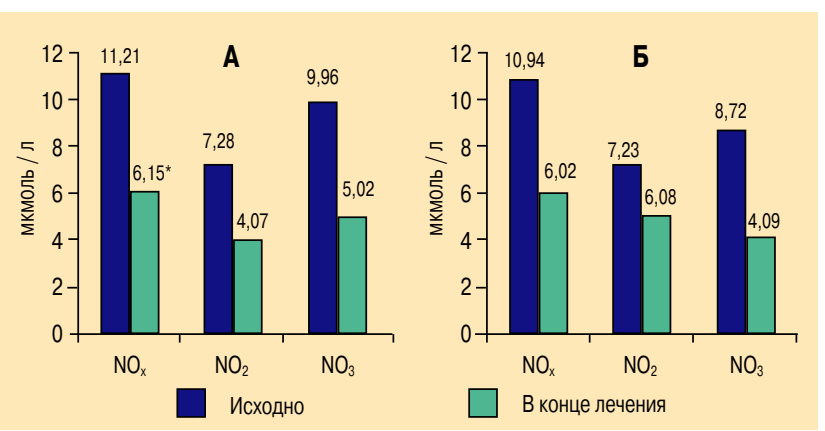

Рис. 4. Изменения показателей слюны (конечные стабильные метаболиты NO) в обеих группах (А - группа фенспирида, Б контрольная группа) до и после лечения

Примечание: * - $p<0,05$ по сравнению с исходными данными.

Таким образом, в результате проведенного исследования удалось установить, что при длительном лечении противовоспалительным препаратом фенспирид у больных ХОБЛ ранних стадий улучшается клиническая симптоматика, изменяются показатели секреторного иммунитета слюны: снижается уровень белков острой фазы (лактоферрина) и провоспалительных цитокинов (IL-8), повышается концентрация бактерицидных факторов слюны (белка муцина) и прослеживается тенденция к изменению уровня NO, способствующего бронходилатации в большей степени крупных бронхов. Отмечен достоверный рост значения ОФВ

\section{Заключение}

В связи с тем, что в период клинической ремиссии заболевания у пациентов с ХОБЛ выявляются признаки воспаления в бронхиальном дереве, противовоспалительная терапия должна быть обязательной составляющей в базовом лечении. Препарат фенспирид обладает выраженным противовоспалительным действием и, как следствие, уменьшает выраженность клинических признаков заболевания и достоверно увеличивает ОФВ 1 . Полученные данные свидетельствуют о целесообразности использования фенспирида в лечении больных ХОБЛ ранних стадий.

\section{Литература}

1. Чучалин А.Г. (ред.). Хроническая обструктивная болезнь легких: Практ. рекомендации. М.: Атмосфера; 2003.

2. Шмелев Е.И. Хроническая обструктивная болезнь легких. М.; 2003.

3. Айсанов 3.Р., Кокосов А.Н., Овчаренко С.И. и др. Хронические обструктивные болезни легких. Федеральная программа. Рус. мед. журн. 2001; 9 (1): 9-32.

4. Miravitlles M., Espinosa C., Fernandez-Laso E. Relationship between bacterial flora in sputum and functional impairment in patients with acute exacerbations of COPD. Study group of bacterial infection in COPD. Chest 1999; 116 (1): 40-46.

5. Agusti A.G.N. COPD, a multicomponent disease: implications for management. Respir. Med. 2005; 99: 670-682.

6. Копьева Т.Н., Бармина Г.В., Свищев А.В., Макарова О.В. Морфология и патогенез хронического бронхита. Арх. пат. 1989; 7: 83. 
7. Cole P., Wilson R. Host-microbal interrelationships in respiratory infection. Chest 1989; suppl.: 217-221.

8. Орлова Е.A. Клинико-диагностические исследования лактоферрина при неспецифических заболеваниях легких. Астрахань; 1996; т. 4: 97-100.

9. Степанищева Л.А. Клинико-иммунологические особенности хронической обструктивной болезни легких, стратификация риска и реабилитация рабочих машиностроительного предприятия: Автореф. дис. ... д-ра мед. наук. Самара; 2005.

10. Hill A.T., Bayley D., Stockley R.A. The interrelationship of sputum inflammatory markers in patients with chronic bronchitis. Am. J. Respir. Crit. Care Med. 1999; 160: 893-898.

11. Immunology. 7-th ed. / Male D., Brostoff J., Roth D.B. et.al. St. Louis: Mosby Elsevier; 2006. 163-181.

12. Andersson F., Borg S., Jansson S.A. et al. The costs of exacerbations in chronic obstructive pulmonary disease (COPD). Respir. Med. 2002; 96: 700-708.

13. Nijkamp F.P., Folkerts G. Nitric oxide and bronchial reactivity. Clin. Exp.Allergy. 1994; 24 (10): 905-914.

14. Kagan V.E., Gleiss B., Tyurina Y. et al. A role for oxidative stress in apoptosis: oxidation and externalization of phosphatidylserine is required for macrophage clearance of cells undergoing Fas - mediated apoptosis. J. Immunol. 2002; 169: 487-499.
15. Bhowmik A., Seemungal T.A.R., Sapsford R.J. et al. Relation of sputum inflammatory markers to symptoms and physiological changes at COPD exacerbations. Thorax 2000; 55: 114-200.

16. Сухарев А.Е., Николаев А.А., Васильев М.Ю. Уровень сывороточного лактоферрина в норме и при патологии. Вопр. мед. химии 1990; 3: 81-83.

17. Трубников Г.А. Иммунохимические маркеры воспаления и опухолей в клинической пульмонологии. Астрахань: изд-во АГМА; 2000.

18. Немцова Е.Р., Якубовская Р.И., Уткин М.М. Иммунохимическое сравнение лактоферрина женского молока и лактоферрина нейтрофилов. Вопр. мед. химии 1998; 3: 127-131.

19. Kolb E. Recent knowledge of the structure and function of lactoferrin. Z. Ges. Inn. Med. 1989; 44 (12): 345-350.

20. Borg G. Psychophisical bases of perceived exertion. Med. Sci. Sport Exerc. 1982; 14: 436-447.

21. Чучалин А.Г. Клинические рекомендации по хронической обструктивной болезни легких. М.: Колор Ит Студио; 2001.

22. Айсанов 3.Р. Исследование респираторной функции. В кн.: Чучалин А.Г. (ред.). Клинические рекомендации. Хроническая обструктивная болезнь легких. М.: Атмосфера; 2003. 28-32.

Поступила 15.05.08 () Коллектив авторов, 2008 удк 616.24-036.12-085.281-092 